\title{
DIFFERENT PHYSICAL PROPERTIES OF FEW AMINO ACIDS FOR FIVE DIFFERENT TEMPERATURES IN AQUEOUS SODIUM ACETATE SOLUTION
}

\author{
Richard D' Souza \\ Research Scholar, Department of Physics, \\ Bharathiyar University, Coimbatore, Tamil Nadu, India. \\ G. Meenakshi \\ Associate Professor (Rtd), Department of Physics, \\ Kanchimamunivar Center for PG Studies, Pondicherry, India
}

\begin{abstract}
In this paper we have considered two basic amino acids and obtained the physical property like ultrasonic velocity. Though the main focus of the paper is ultrasonic velocity, but other physical parameters like adiabatic compressibility, apparent molal compressibility, apparent molal volume, limiting apparent molal compressibility, limiting apparent molal volume and their constants, transfer adiabatic compressibility, transfer volume, and viscosity B-coefficient of Jones-Dole equation are obtained in sodium acetate solution. From our study, it is quite clear that temperature has a significant effect on the structure of the amino acids. We have considered two basic amino acids, namely, L-leucine and L-glutamine under the influence of five different temperatures as $300 \mathrm{~K}, 305 \mathrm{~K}, 310 \mathrm{~K}, 315$ and $320 \mathrm{~K}$.
\end{abstract}

Keywords: L-glutamine, L-leucine, sodium acetate, ultrasonic velocity

Cite this Article: Richard D' Souza and G. Meenakshi, Different Physical Properties of Few Amino Acids for Five Different Temperatures in Aqueous Sodium Acetate Solution, International Journal of Advanced Research in Engineering and Technology, 10(1), 2019, pp. 181-187.

http://iaeme.com/Home/issue/IJARET?Volume=10\&Issue=1

\section{INTRODUCTION}

Since last few years, basic structure of proteins is in the focus. As it is not easy to study the structure of protein directly, it is more convenient to examine simpler amino acids as they are the basic components of protein. The study of different physical structures can lead to the more clear understanding of the structure and also the changes and evolution of protein [1-2]

L-leucine and L-glutamine both are essential alpha amino acid i.e. both of them contain an alpha 
Amino group and an alpha carboxylic acid group [3]. In order to study or examine the amino acids directly; we used sodium acetate solution to produce aqueous solution of the amino acids [4]. The main focus of our study is to examine the ultrasonic velocity but other physical characteristics like adiabatic compressibility, apparent molal compressibility, apparent molal volume, limiting apparent molal compressibility, limiting apparent molal volume and their constants, transfer adiabatic compressibility, transfer volume, and viscosity B-coefficient of Jones-Dole equation will also be studied in five different temperatures as $300 \mathrm{~K}, 305 \mathrm{~K}, 310 \mathrm{~K}$, $315 \mathrm{~K}$ and $320 \mathrm{~K}$ of two basic amino acids L-leucine and L-glutamine.

\section{EXPERIMENTAL DETAILS}

The spectroscopic regents and analytical grade with a least assay of 99.9 percent were used in this paper and obtained from E-Merck, Germany and Sd Fine chemicals; India. The used water was distilled, de ionized and degassed for better experimental result. The required amount of $\mathrm{n}$ propanol solution were taken at a concentration range of $0.2-0.4 \mathrm{~mol} / \mathrm{dm}^{3}$. The amino acids, L-leucine and L-glutamine were dissolved in the solutions. Digital electronic balance (Model: Shimadzu Ax - 200) was used with a precision of $\pm 1 \times 10^{-4} \mathrm{~g}$ to measure the reagent.

An Ostwald's viscometer $(5 \mathrm{ml})$ was used to measure the viscosity and the density was measured by using a specific gravity bottle using the relative measurement method.

A digital chronometer within $\pm 0.01 \mathrm{~s}$ was used to determine the Efflux time. Ultrasonic interferometer having a frequency of $3 \mathrm{MHz}$ with an accuracy of $0.1 \%$ was used for velocity measurements and also a digital electronic constant temperature with $\pm 0.1 \mathrm{~K}$ accuracy was used for experimental purpose.

\section{RESULT AND DISCUSSIONS}

Ultrasonic velocity, adiabatic compressibility, apparent molal compressibility, apparent molal volume, limiting apparent molal compressibility, limiting apparent molal volume and their constants, transfer adiabatic compressibility, transfer volume, and viscosity B-coefficient of jones-Dole equation are obtained and reported in different following tables for five different temperatures $300 \mathrm{~K}, 305 \mathrm{~K}, 310 \mathrm{~K}, 315 \mathrm{~K}$ and $320 \mathrm{~K}$ for .

The adiabatic compressibility is given by the equation,

$$
\beta=\frac{1}{U^{2} \rho}
$$

Where, $U=$ ultrasonic velocity, $\rho=$ density.

The apparent molal compressibility is,

$$
\phi_{k}=\frac{1000}{m \rho_{o}}\left(\rho_{o} \beta-\rho \beta_{o}\right)+\frac{\beta_{o} M_{w}}{\rho_{o}}
$$

Where $\beta, \phi_{\mathrm{v}}, \phi_{\mathrm{k},}, \phi_{\mathrm{v}}^{\circ}, \phi_{\mathrm{k}}^{\circ}, \mathrm{m}$ and $\mathrm{M}_{\mathrm{w}}$ corresponds to the value of adiabatic compressibility, apparent molal volume, apparent molal compressibility, limiting apparent molal volume, limiting apparent molal compressibility, the molal concentration and the molecular weight of the solute respectively. $\varphi_{\mathrm{k}}$ is the function of $\mathrm{M}$ as shown by Gucker (1933)[5],

$$
\phi_{k}=\phi_{k}^{o}+s_{k} M^{\frac{1}{2}}
$$

Where, $\varphi^{\circ}$ is the limiting apparent molal compressibility and $S_{k}$ is a constant. The apparent molal volume $\varphi_{\mathrm{v}}$ can be written as, 
Different Physical Properties of Few Amino Acids for Five Different Temperatures in Aqueous Sodium Acetate Solution

$$
\phi_{v}=\frac{1000}{m \rho_{o}}\left(\rho_{o}-\rho\right)+\frac{M}{\rho_{o}}
$$

Using Masson's empirical relation one can have [6],

$$
\phi_{v}=\phi_{v}^{o}+S_{v} M^{\frac{1}{2}}
$$

Where, $\varphi_{\mathrm{v}}^{\mathrm{o}}$ is the limiting apparent molal volume and $\mathrm{S}_{\mathrm{v}}$ is a constant. The viscosity data can be analyzed using Jones-Dole semi empirical equation [7],

$$
\frac{\eta}{\eta_{o}}=1+A m^{\frac{1}{2}}+B m
$$

Where A and B are the coefficients of viscosity, $\eta$ is the viscosity of the solution and $\eta_{\mathrm{o}}$ is the viscosity of the solvent.

\begin{tabular}{|c|c|c|c|c|c|c|c|c|c|c|c|c|c|c|c|}
\hline \multirow{3}{*}{$\begin{array}{c}\text { Molality } \\
\mathrm{m} \\
\left(\mathrm{mol} \mathrm{kgg}^{-1}\right)\end{array}$} & \multicolumn{5}{|c|}{ Density $\mathrm{p} /\left(\mathrm{kg} \cdot \mathrm{m}^{3}\right)$} & \multicolumn{5}{|c|}{ Viscosity $\eta /\left(10^{-3} \cdot \mathrm{Nsm}^{-2}\right)$} & \multicolumn{5}{|c|}{ Ultrasonic velocity $\mathrm{U} /\left(10^{-10} \mathrm{~m} . \mathrm{s}^{-1}\right)$} \\
\hline & \multicolumn{5}{|c|}{ Temperature $(\mathrm{K})$} & \multicolumn{5}{|c|}{ Temperature $(\mathrm{K})$} & \multicolumn{5}{|c|}{ Temperature $(\mathrm{K})$} \\
\hline & 300 & 305 & 310 & 315 & 320 & 300 & 305 & 310 & 315 & 320 & 300 & 305 & 310 & 315 & 320 \\
\hline 0.00 & 1007.1 & 999.2 & 994.01 & 991.1 & 987.2 & 1.0900 & 0.985 & 0.7190 & 0.569 & 0.4900 & 1536.1 & 1539.3 & 1541.6 & 1543.5 & 1546.0 \\
\hline 0.02 & 1009.1 & 1001.3 & 996.09 & 993.02 & 989.1 & 1.0920 & 0.995 & 0.7250 & 0.585 & 0.4100 & 1537.0 & 1540.1 & 1542.9 & 1544.3 & 1547.0 \\
\hline 0.04 & 1012.99 & 1003.5 & 999.00 & 995.5 & 991.3 & 1.0930 & 1.015 & 0.7360 & 0.608 & 0.4230 & 1537.9 & 1540.8 & 1543.5 & 1545.0 & 1547.8 \\
\hline 0.06 & 1014.1 & 1005.5 & 1001.1 & 997.2 & 993.4 & 1.0950 & 1.035 & 0.7470 & 0.619 & 0.4330 & 1538.5 & 1541.9 & 1544.2 & 1546.1 & 1548.3 \\
\hline 0.08 & 1015.99 & 1008.1 & 1003.3 & 999.08 & 9950 & 1.0960 & 1.054 & 0.7600 & 0.623 & 0.4450 & 1539.1 & 1543.0 & 1545.0 & 1547.3 & 1549.1 \\
\hline 0.10 & 1017.1 & 1010.20 & 1006.20 & 1002.0 & 997.3 & 1.0980 & 1.071 & 0.7720 & 0.640 & 0.4500 & 1540.0 & 1544.1 & 1546.0 & 1548.1 & 1550.0 \\
\hline
\end{tabular}

Table 1 Density $(\rho)$, viscosity $(\eta)$ and ultrasonic velocity (U) for L-leucine with the temperature varying $300 \mathrm{~K}, 305 \mathrm{~K}, 310 \mathrm{~K}, 315 \mathrm{~K}$ and $320 \mathrm{~K}$ for all the three columns.

It can be seen from Table 1 that the density increases with the increase of the molality of Lleucine amino acid for every individual temperature $300 \mathrm{~K}, 305 \mathrm{~K}, 310 \mathrm{~K}, 315 \mathrm{~K}$ and $320 \mathrm{~K}$ but the density decreases as the temperature increases. Exactly same observation can be seen for viscosity i.e. viscosity decreases with temperature and increases with density. On the other hand, the ultrasonic velocity increases with the increase of the temperature and also increases with the increase of density. 
Table 2 Density $(\rho)$, viscosity $(\eta)$ and ultrasonic velocity $(\mathrm{U})$ for L-glutamine with the temperature varying $300 \mathrm{~K}, 305 \mathrm{~K}, 310 \mathrm{~K}, 315 \mathrm{~K}$ and $320 \mathrm{~K}$ for all the three columns.

\begin{tabular}{|c|c|c|c|c|c|c|c|c|c|c|c|c|c|c|c|}
\hline \multirow{3}{*}{$\begin{array}{c}\text { Molality } \\
\mathrm{m} \\
\text { (mol. } \mathrm{kg}^{-1} \text { ) }\end{array}$} & \multicolumn{5}{|c|}{ Density $\rho /\left(\mathrm{kg}^{\prime} \mathrm{m}^{-3}\right)$} & \multicolumn{5}{|c|}{ Viscosity $\eta /\left(10^{-3}, \mathrm{Nsm}^{-2}\right)$} & \multicolumn{5}{|c|}{ Ultrasonic velocity $\mathrm{U} /\left(10^{-10} \mathrm{~m} \cdot \mathrm{s}^{-1}\right)$} \\
\hline & \multicolumn{5}{|c|}{ Temperature(K) } & \multicolumn{5}{|c|}{ Temperature(K) } & \multicolumn{5}{|c|}{ Temperature(K) } \\
\hline & 300 & 305 & 310 & 315 & 320 & 300 & 305 & 310 & 315 & 320 & 300 & 305 & 310 & 315 & 320 \\
\hline 0.00 & 990.1 & 984.3 & 980.1 & 974.1 & 968.4 & 1.1200 & 1.0800 & 0.9614 & 0.767 & 0.5900 & 1525.0 & 1531.4 & 1537.6 & 1540.0 & 1546.0 \\
\hline 0.02 & 993.0 & 986.3 & 984.3 & 976.2 & 970.2 & 1.1330 & 1.0830 & 0.9714 & 0.789 & 0.6200 & 1526.1 & 1532.2 & 1538.6 & 1541.2 & 1547.9 \\
\hline 0.04 & 995.2 & 988.9 & 986.3 & 978.4 & 972.3 & 1.1450 & 1.0850 & 0.9814 & 0.791 & 0.6250 & 1527.0 & 1533.0 & 1539.6 & 1542.0 & 1548.8 \\
\hline 0.06 & 997.4 & 991.0 & 988.1 & 980.3 & 974.3 & 1.1570 & 1.0870 & 0.9814 & 0.805 & 0.6330 & 1527.9 & 1534.3 & 1540.2 & 1543.1 & 1549.7 \\
\hline 0.08 & 999.0 & 993.3 & 990.2 & 982.4 & 976.1 & 1.1680 & 1.0880 & 1.0614 & 0.820 & 0.6400 & 1528.8 & 1535.4 & 1541.1 & 1544.2 & 1550.9 \\
\hline 0.10 & 1001.1 & 995.1 & 992.3 & 984.2 & 978.1 & 1.1700 & 1.0900 & 1.1614 & 0.832 & 0.6500 & 1529.9 & 1536.1 & 1542.3 & 1545.1 & 1551.0 \\
\hline
\end{tabular}

We have calculated the data related to density, viscosity and the ultrasonic speed of the solution with the alteration in the molality of L-glutamine amino acid and produces them in Table 2 for the temperatures $300 \mathrm{~K}, 305 \mathrm{~K}, 310 \mathrm{~K}, 315 \mathrm{~K}$ and $320 \mathrm{~K}$. It can be seen, just like Lleucine, the density increases with the increase in the molality and decreases with the increase in temperature. Similarly, the viscosity decreases with temperature and increases with the increase of molality. The ultrasonic velocity also increases with the increase of molality and also increases with the increase of the temperature. Our study was found to be consistent with the one reported by Mirikar et al., where it was reported that density and ultrasonic velocity is dependent on temperature [8]. Sumathi et al., reported that the ultrasonic velocity, density and viscosity increases with the increased amino acid concentration in all the systems [9].

It is quite clear that if we increase the concentration, the density will automatically increase. But the viscosity is also increase with the increase of molality. The reason for that may be, to maintain the structure of the solution. The increase in concentration of the solute may lead to the formation of increased hydrogen bonding among the solute-solvent. This increased hydrogen may affect the overall structure of the solution and also the solute-solvent interaction. When the amino acids are dissolved in the water, it gives rise to the cohesion of the solution and this cohesion may be the reason for increased ultrasonic velocity. When the concentration of the solute increased, it gives rise to more cohesion which directly may lead to the increased ultrasonic velocity. One interesting thing is that the ultrasonic velocity also increases with the increase of the temperature. This may happened due to the increased kinetic energy of the ions with the increased temperature. These explanations are true for both the amino acids (L-leucine and L-glutamine) we have taken in account. 
Different Physical Properties of Few Amino Acids for Five Different Temperatures in Aqueous Sodium Acetate Solution

Table 3 Values of adiabatic compressibility $(\beta)$, apparent molal compressibility $\left(\varphi_{\mathrm{k}}\right)$ and apparent molal volume $\left(\varphi_{\mathrm{v}}\right)$ of L-leucine with the temperature varying $300 \mathrm{~K}, 305 \mathrm{~K}, 310 \mathrm{~K}, 315 \mathrm{~K}$ and $320 \mathrm{~K}$.

\begin{tabular}{|c|c|c|c|c|c|c|c|c|c|c|c|c|c|c|c|}
\hline \multirow{3}{*}{$\begin{array}{l}\text { Molalilit } \\
\text { y m } \\
\text { (mol.k } \\
\mathrm{g}: \text { ) }\end{array}$} & \multicolumn{5}{|c|}{ compressibility $\beta /\left(x_{10} 0^{-10} \mathrm{~m}^{2} \mathrm{~N}^{-1}\right)$} & \multicolumn{5}{|c|}{ molal compressibility $-v_{0} /\left(\mathrm{x}_{10} 10^{-7} \mathrm{~m}^{2} \mathrm{~N}^{-1}\right)$} & \multicolumn{5}{|c|}{ apparent molar volume $-Q \mathrm{Q}\left(\mathrm{x} 10^{-3} \mathrm{~m}^{3} \mathrm{~mol} \mathrm{l}^{-1}\right)$} \\
\hline & \multicolumn{5}{|c|}{ Temperature(K) } & \multicolumn{5}{|c|}{ Temperature( $(\mathrm{K})$} & \multicolumn{5}{|c|}{ Temperature $(\mathrm{K})$} \\
\hline & 300 & 305 & 310 & 315 & 320 & 300 & 305 & 310 & 315 & 320 & 300 & 305 & 310 & 315 & 320 \\
\hline 0.00 & & & & 4.3495 & 4.3 & 3.2335 & 2725 & 3.3179 & 3.3455 & 3.3844 & & & & 244.01 & 256.1 \\
\hline 0.02 & 4.2353 & 2789 & 4.3142 & 4.3485 & 4.3711 & 3.2315 & 3.2710 & 3.2879 & 3.3430 & 3.3800 & 182.3 & 206.5 & 227.01 & 234.01 & 246.9 \\
\hline 0.04 & 4.2334 & 4.2781 & 4.3136 & 4.3475 & 4.379 & 3.2300 & 3.2790 & 3.2789 & 3.3410 & 3.3750 & 173.9 & 192.6 & 219.01 & 221.01 & 231.4 \\
\hline 0.06 & 4.2321 & 4.2775 & 4.3126 & 4.3465 & 4.3780 & 3.2985 & 3.2775 & 3.2669 & 3.3493 & 3.3760 & 160.5 & 180.8 & 211.01 & 209.01 & 223.7 \\
\hline 0.08 & 4.2309 & 4.2766 & 4.3117 & 4.3455 & 4.3770 & 3.1935 & 3.2760 & 3.2579 & 4.3479 & 3.3700 & 149.2 & 167.5 & 201.01 & 199.0 & 211.4 \\
\hline 0.10 & 4.2295 & 4.2754 & 4.3105 & 4.3445 & 4.3760 & 3.1900 & 3.2745 & 3.2470 & 3.6463 & 3.3680 & 140.01 & 158.9 & 189.01 & 191.5 & 2000.0 \\
\hline
\end{tabular}

In Table 3 we have produced the data of the adiabatic compressibility, molal compressibility and the apparent molal volume with respect to the increase of the molal concentration of the Lleucine amino acid and increase of the temperature with respect to five different temperatures $300 \mathrm{~K}, 305 \mathrm{~K}, 310 \mathrm{~K}, 315 \mathrm{~K}$ and $320 \mathrm{~K}$. From the table it is quite clear that all these three quantities increase with increase of temperature but decrease with the increase of molality. The molal compressibility and the apparent molal volume are negative for L-leucine amino acid.

Table 4 Values of adiabatic compressibility $(\beta)$, apparent molar compressibility $\left(\varphi_{\mathrm{k}}\right)$ and apparent molal volume $\left(\varphi_{\mathrm{v}}\right)$ of L-Glutamine with the temperature varying $300 \mathrm{~K}, 305 \mathrm{~K}, 310 \mathrm{~K}, 315 \mathrm{~K}$ and $320 \mathrm{~K}$.

\begin{tabular}{|c|c|c|c|c|c|c|c|c|c|c|c|c|c|c|c|}
\hline \multirow{3}{*}{$\begin{array}{c}\text { Molality } \\
\text { m } \\
(\mathrm{mol} . \mathrm{kg} \\
\text { l) }\end{array}$} & \multicolumn{5}{|c|}{ compressibility $\beta /\left(\mathrm{x}_{10} 0^{-10} \mathrm{~m}^{2} \mathrm{~S}^{-1}\right)$} & \multicolumn{5}{|c|}{ molal compressibility $-\varphi_{z}\left(\mathrm{x} \quad 10^{-7} \mathrm{~m}^{2} \mathrm{~N}^{-1}\right)$} & \multicolumn{5}{|c|}{ apparent molar volume $-\varphi_{v}\left(\mathrm{x}^{1} 0^{-3} \mathrm{~m}^{3} \mathrm{mo}^{-1}\right)$} \\
\hline & \multicolumn{5}{|c|}{ Temperature(K) } & \multicolumn{5}{|c|}{ Temperature(K) } & \multicolumn{5}{|c|}{ Temperature(K) } \\
\hline & 300 & 305 & 310 & 315 & 320 & 300 & 305 & 310 & 315 & 320 & 300 & 305 & 310 & 315 & 320 \\
\hline 0.00 & 4.1092 & 4.1598 & 4.2791 & 4.3955 & 4.4210 & 3.2203 & 3.4430 & 3.5430 & 3.6694 & 3.6789 & 301.1941 & 304.2511 & 308.6400 & 310.5501 & 313.2571 \\
\hline 0.02 & 4.0953 & 4.1476 & 4.2722 & 4.3900 & 4.3700 & 3.2100 & 3.4323 & 4.5330 & 3.6394 & 3.6700 & 301.1942 & 304.2512 & 308.6401 & 310.5502 & 313.2572 \\
\hline 0.04 & 4.0500 & 4.1048 & 4.1956 & 4.3899 & 4.3570 & 3.1900 & 3.4201 & 4.5130 & 3.6100 & 3.6660 & 301.1943 & 304.2513 & 308.6402 & 310.5503 & 313.2573 \\
\hline 0.06 & 4.0200 & 4.0915 & 4.1900 & 4.3500 & 4.3170 & 3.1518 & 3.4100 & 4.4900 & 3.5891 & 3.6460 & 301.1944 & 304.2514 & 308.6403 & 310.5504 & 313.2574 \\
\hline 0.08 & 3.8920 & 3.9056 & 4.1460 & 3.3100 & 4.2620 & 3.1295 & 3.3600 & 4.4756 & 3.5655 & 3.6200 & 301.1945 & 304.2515 & 308.6404 & 310.5505 & 313.2575 \\
\hline 0.10 & 3.8600 & 3.8756 & 3.9000 & 3.2900 & 4.2050 & 3.1000 & 3.3421 & 4.4234 & 3.5600 & 3.5880 & 301.1948 & 304.2516 & 308.6405 & 310.5506 & 313.2576 \\
\hline
\end{tabular}

Table 4 describes the changes in the adiabatic compressibility, molal compressibility and the apparent molal volume with the increase of the molal concentration of the L-glutamine amino acid for five different temperatures $300 \mathrm{~K}, 305 \mathrm{~K}, 310 \mathrm{~K}, 315 \mathrm{~K}$ and $320 \mathrm{~K}$. The adiabatic compressibility for the L-glutamine amino acid decreases with the increase of the molality.

Just like L-leucine, the molal compressibility and apparent molar volume of the L-glutamine amino acid are also observed negative. The molal compressibility, molar compressibility and apparent molal volume of the L-glutamine amino acid have been seen to increase with the increase of temperature. The molal compressibility is found to be decreased with the increase molality of L-glutamine amino. On the other hand, the apparent molar volume increases with the increase of molality. Hedaoo et al., reported that the increased apparent molal compressibility was found to decrease with the increased concentrations of the amino acids indicating a weak electrostatic force in the ionic environment leading to the electrostatic salvation of ions [10] The hydrophilic interaction leads to the negative values of molal 
compressibility and apparent molar volume for both the amino acids L-leucine and L-glutamine [11]. The temperature has a very affective role on both these physical characteristics of the amino acids.

Table 5 Values of limiting apparent molal volume $\left(\varphi_{\mathrm{v}}^{\mathrm{o}}\right)$ and constant $\mathrm{S}_{\mathrm{v}}$ with the temperature varying from $300 \mathrm{~K}, 305 \mathrm{~K}, 310 \mathrm{~K}, 315 \mathrm{~K}$ and $320 \mathrm{~K}$.

\begin{tabular}{|c|c|c|c|c|c|c|c|c|c|c|}
\hline \multirow{3}{*}{$\begin{array}{l}\text { Amino } \\
\text { acids }\end{array}$} & \multicolumn{5}{|c|}{$\begin{array}{c}\text { limiting apparent molal volume } \varphi_{\mathrm{v}}^{0} /\left(\mathbf{x} \mathbf{1 0}^{-8} \mathrm{~m}^{2}\right. \\
\left.\mathrm{N}^{-1}\right)\end{array}$} & \multicolumn{5}{|c|}{ constants $S_{v} /\left(\times 10^{-8} \mathrm{~m}^{-1} \mathrm{~N}^{-1} \mathrm{~mol}^{-1}\right)$} \\
\hline & \multicolumn{5}{|c|}{ Temperature $(\mathrm{K})$} & \multicolumn{5}{|c|}{ Temperature $(\mathrm{K})$} \\
\hline & 300 & 305 & 310 & 315 & 320 & 300 & 305 & 310 & 315 & 320 \\
\hline L-leucine & $\begin{array}{c}- \\
209.030\end{array}$ & $\begin{array}{c}- \\
209.035\end{array}$ & $\begin{array}{c}- \\
209.04\end{array}$ & $\begin{array}{c}- \\
209.045\end{array}$ & $\begin{array}{c}- \\
209.050\end{array}$ & 336.60 & 336.65 & 336.75 & 336.65 & 336.57 \\
\hline $\begin{array}{c}\text { L- } \\
\text { Glutamine }\end{array}$ & -297.60 & -297.65 & -297.7 & -297.75 & -297.80 & 0.6242 & 0.6246 & 0.6254 & 0.6247 & 0.6240 \\
\hline
\end{tabular}

Table 5 represents the values of the limiting apparent molal volume and the constants $\mathrm{S}_{\mathrm{k}}$ for L-leucine and L-Glutamine amino acids. The limiting apparent molal volume of the L-leucine and L-Glutamine amino acids can be observed to be increase with temperature. Similarly the constants $\mathrm{S}_{\mathrm{v}}$ for L-leucine and L-glutamine amino acids are increases with temperature then decreases with further increase of temperature.

Table 6 Values of limiting apparent molal volume $\left.\left(\varphi^{\circ}\right)\right)$, their constant $S_{k}$ with the temperature varying $300 \mathrm{~K}, 305 \mathrm{~K}, 310 \mathrm{~K}, 315 \mathrm{~K}$ and $320 \mathrm{~K}$.

\begin{tabular}{|c|c|c|c|c|c|c|c|c|c|c|}
\hline \multirow{3}{*}{$\begin{array}{l}\text { Amino } \\
\text { acids }\end{array}$} & \multicolumn{5}{|c|}{$\begin{array}{c}\text { limiting apparent molal compressibility } \\
\qquad \varphi^{0} /\left(\mathrm{x} \mathrm{m}^{3} \mathrm{~mol}^{-1}\right)\end{array}$} & \multicolumn{5}{|c|}{ constants $S_{k} /\left(x^{-1} \mathbf{N}^{-1} \mathbf{m o l}^{-1}\right)$} \\
\hline & \multicolumn{5}{|c|}{ Temperature $(\mathrm{K})$} & \multicolumn{5}{|c|}{ Temperature $(\mathrm{K})$} \\
\hline & 300 & 305 & 310 & 315 & 320 & 300 & 305 & 310 & 315 & 320 \\
\hline L-leucine & $\begin{array}{c}- \\
2.7638\end{array}$ & $\begin{array}{c}- \\
2.7630 \\
\end{array}$ & $\begin{array}{c}- \\
2.7621\end{array}$ & $\begin{array}{c}- \\
2.7613 \\
\end{array}$ & $\begin{array}{c}- \\
2.7601\end{array}$ & 3.4966 & 3.4964 & 3.4966 & 3.4968 & 3.4970 \\
\hline $\begin{array}{c}\text { L- } \\
\text { Glutamine }\end{array}$ & $\begin{array}{c}- \\
3.9061\end{array}$ & - & $\begin{array}{c}- \\
3.8987\end{array}$ & $\begin{array}{c}- \\
3.8960\end{array}$ & $\begin{array}{c}- \\
3.8940\end{array}$ & 7.1843 & 7.1950 & 7.2800 & 7.2930 & 7.2710 \\
\hline
\end{tabular}

Table 6 shows the limiting apparent molal compressibility and the constants for L-leucine and L-glutamine amino acids. The limiting apparent molal compressibility and the related constant of the L-leucine and the L-glutamine amino acids decreased with the increase of the temperature.

Again the negative values of limiting apparent molal compressibility and limiting apparent molal volume re confirm our previous conclusion of hydrophobic and ionic reactions for both the amino acids.

\section{CONCLUSION}

The study concluded that the molal compressibility, molar compressibility and apparent molal volume of the L-glutamine and L-leucine amino acid increased with the increase of temperature. The limiting apparent molal compressibility and the related constant of the L-leucine and the L-glutamine amino acids also decreased with the increase of the temperature. The increased temperature was observed to decrease the molal compressibility, apparent molar volume, limiting apparent molal compressibility and volume of both the L-glutamine and L-leucine amino acids as a result of the decreased ionic interactions among the solutes due to increased temperature. The ultrasonic velocities of the L-glutamine and L-leucine amino acids were found to increase with the increased concentration and temperature of the amino acids in the solutions. 
Different Physical Properties of Few Amino Acids for Five Different Temperatures in Aqueous Sodium Acetate Solution

\section{REFERENCES}

[1] Khanlarzadeh K, Iloukhani $\mathrm{H}$. Thermo-acoustical and volumetric studies on interionic interactions of 1-histidine in aqueous maltose solutions at different temperatures. Journal of Molecular Liquids. 2018;271:421-8.

[2] Scheraga HA, Rackovsky S. Global informatics and physical property selection in protein sequences. Proceedings of the National Academy of Sciences of the United States of America. 2016;113(7):1808-10.

[3] Lundblad RL, Macdonald F. Handbook of biochemistry and molecular biology: CRC Press; 2018.

[4] Thirumaran S, Inbam P. Thermodynamic and transport studies on some basic amino acids in aqueous sodium acetate solution at different temperatures. Indian Journal of Pure and Applied Physics. 2011;49(7):451-9.

[5] Gucker FT. The Apparent Molal Heat Capacity, Volume, and Compressibility of Electrolytes. Chemical Reviews. 1933;13(1):111-30.

[6] Masson DO. XXVIII. Solute molecular volumes in relation to solvation and ionization. The London, Edinburgh, and Dublin Philosophical Magazine and Journal of Science. 1929;8(49):218-35.

[7] Jones G, Dole M. The viscosity of aqueous solutions of strong electrolytes with special reference to barium chloride. Journal of the American Chemical Society. 1929;51(10):2950-64.

[8] Mirikar S, Pawar P, Bichile G. Ultrasonic Velocity, Density and Viscosity Measurement of Amino Acid in Aqueous Electrolytic Solutions at 308.15 K. American Journal of Pharmacology and Pharmacotherapeutics. 2013;2(1):019-25.

[9] Sumathi T, Varalakshmi M. Ultrasonic velocity, density and viscosity measurement of methionine in aqueous electrolytic solutions at 303k. Rasayan Journal of Chemistry. 2010;3(3):550-5.

[10] Hedaoo D, Kalaskar M, Wadekar M. Adiabatic compressibility, apparent molal volume, apparent molal compressibility and solvation number of 2, 3-Dihydroquinazolin-4 (1H)-one derivatives in 70\% DMF-Water. Advances in Applied Science Research. 2015;6(6):81-8.

[11] Rani R, Kumar A, Sharma T, Saini B, Bamezai RK. Interactions of L-Aspartic Acid with Aqueous Solution of 1, 2-Propanediol at Different Temperatures: A Volumetric, Compressibility and Viscometric Approach. Acta Chimica Slovenica. 2016;63(3):589-601. 